\title{
Sodium pyrophosphate enhances iron bioavailability from bouillon cubes fortified with ferric pyrophosphate
}

\author{
Colin I. Cercamondi ${ }^{1 *}$, Guus S. M. J. E. Duchateau ${ }^{2}$, Rajwinder K. Harika ${ }^{2}$, Robin van den Berg ${ }^{2}$, \\ Peter Murray ${ }^{2}$, Wieneke P. Koppenol ${ }^{2}$, Christophe Zeder ${ }^{1}$, Michael B. Zimmermann ${ }^{1}$ and Diego Moretti ${ }^{1}$ \\ ${ }^{1}$ Laboratory of Human Nutrition, Institute of Food, Nutrition and Health, ETH Zurich, 8092 Zurich, Switzerland \\ ${ }^{2}$ Unilever RED, 3133 Vlaardingen, The Netherlands
}

(Submitted 18 December 2015 - Final revision received 20 April 2016 - Accepted 9 May 2016 - First published online 8 June 2016)

\section{Abstract}

Fe fortification of centrally manufactured and frequently consumed condiments such as bouillon cubes could help prevent Fe deficiency in developing countries. However, Fe compounds that do not cause sensory changes in the fortified product, such as ferric pyrophosphate (FePP), exhibit low absorption in humans. Tetra sodium pyrophosphate (NaPP) can form soluble complexes with Fe, which could increase Fe bioavailability. Therefore, the aim of this study was to investigate Fe bioavailability from bouillon cubes fortified with either FePP only, $\mathrm{FePP}+\mathrm{NaPP}$, ferrous sulphate $\left(\mathrm{FeSO}_{4}\right)$ only, or $\mathrm{FeSO}_{4}+\mathrm{NaPP}$. We first conducted in vitro studies using a protocol of simulated digestion to assess the dialysable and ionic Fe, and the cellular ferritin response in a Caco- 2 cell model. Second, Fe absorption from bouillon prepared from intrinsically labelled cubes $(2.5 \mathrm{mg}$ stable Fe isotopes/cube) was assessed in twenty-four Fe-deficient women, by measuring Fe incorporation into erythrocytes 2 weeks after consumption. Fe bioavailability in humans increased by $46 \%(P<0.005)$ when comparing bouillons fortified with FePP only (4.4\%) and bouillons fortified with FePP + NaPP (6.4\%). Fe absorption from bouillons fortified with FeSO 4 only and with $\mathrm{FeSO}_{4}+\mathrm{NaPP}$ was 33.8 and $27 \cdot 8 \%$, respectively (NS). The outcome from the human study is in agreement with the dialysable Fe from the in vitro experiments. Our findings suggest that the addition of NaPP could be a promising strategy to increase Fe absorption from FePP-fortified bouillon cubes, and if confirmed by further research, for other fortified foods with complex food matrices as well.

Key words: Iron bioavailability: Iron fortification: Ferric pyrophosphate: Bouillon cubes: Sodium pyrophosphate

Fe deficiency (ID) is the most common aetiological factor for anaemia globally, and between 35 and $65 \%$ of the anaemia burden in low-income regions in Africa, Asia and Latin America is attributable to ID $^{(1)}$. Food fortification is regarded as a safe and cost-effective approach to counteract and prevent ID as long as the targeted populations consume significant quantities of industrially manufactured fortified foods ${ }^{(2)}$. Condiments are promising vehicles for fortification as they are among the very few regularly purchased food items in resource-poor areas ${ }^{(3)}$, and Fe-fortified condiments have been shown to be efficacious in improving Fe status ${ }^{(4-7)}$.

Bouillon cubes are a promising vehicle for Fe fortification, particularly in sub-Saharan Africa where previous national surveys have reported a high proportion of Burkinabe, Cameroonian, Nigerian, Senegalese and Ivorian women (79-96\%) who consumed bouillon cubes regularly ${ }^{(8-10)}$. However, ensuring the bioavailability of Fe and the stability of the cubes in these climates is challenging. Water-soluble $\mathrm{Fe}$ compounds such as ferrous sulphate $\left(\mathrm{FeSO}_{4}\right)$ provide the most bioavailable $\mathrm{Fe}$ but induce oxidative rancidity noticeable to consumers at very low levels ${ }^{(11)}$ as well as other unwanted sensorial defects of the product in terms of colour, taste or flavour. In addition, ionic Fe may cause protein precipitation or interact with compounds in the food matrix causing colour changes when the cube is used as a condiment ${ }^{(12)}$. Ferric pyrophosphate (FePP) is a poorly watersoluble $\mathrm{Fe}$ compound that is white and minimally affects sensory properties of fortified foods; its addition to food vehicles produces negligible colour change ${ }^{(13)}$. However, FePP in general is less than half as well absorbed as $\mathrm{FeSO}_{4}$ in humans $^{(14,15)}$. Nevertheless, the efficacy of FePP to reduce anaemia or ID has been shown in several randomised controlled trials ${ }^{(3,6,16-18)}$. Limited evidence exists on potential enhancers of Fe bioavailability from FePP. Addition of ascorbic acid has been shown to increase $\mathrm{Fe}$ bioavailability from FePP $^{(19)}$, but its use in FePP-fortified foods, which are usually cooked, is limited because of the susceptibility to oxidation of vitamin $\mathrm{C}$ into inactive compounds when exposed to air or during heat treatment ${ }^{(20)}$.

Tetra sodium pyrophosphate (NaPP) is a food additive of the complexing agents family that binds minerals and acts as

Abbreviations: AGP, $\alpha$-1-glycoprotein; CRP, C-reactive protein; FePP, ferric pyrophosphate; ID, iron deficiency; NaPP, tetra sodium pyrophosphate; PF, plasma ferritin; sTfR, soluble transferrin receptor.

*Corresponding author: C. Cercamondi, fax +41 44632 14 70, email ccolin@ethz.ch 
a water ligand ${ }^{(21)}$. This binding effect has a positive effect on the sensorial product quality over time. In addition, pyrophosphates such as in NaPP may interact at specific ratios with $\mathrm{Fe}$, as in FePP, forming soluble complexes that remain in solution at neutral $\mathrm{pH}^{(22)}$. This suggests that presence of such soluble Fe complexes could increase in vivo Fe bioavailability. Therefore, to investigate whether NaPP has the potential to enhance Fe bioavailability, we conducted in vitro bioavailability studies followed by an in vivo absorption study with bouillon cubes fortified with either FePP only, FePP $+\mathrm{NaPP}, \mathrm{FeSO}_{4}$ only or $\mathrm{FeSO}_{4}+\mathrm{NaPP}$. The in vitro studies followed a protocol of simulated digestion investigating dialysable and ionic Fe release, and included the cellular ferritin response of the simulated digestion in a Caco-2 cell model. In vivo Fe absorption was assessed in Fe-deficient women using bouillon cubes that were intrinsically labelled with stable $\mathrm{Fe}$ isotopes and by assessing $\mathrm{Fe}$ incorporation of stable isotopic labels at least $14 \mathrm{~d}$ after administration.

\section{Methods \\ Subjects}

The present study was carried out among the student and staff population of ETH Zurich and University Zurich, Switzerland. In all, twenty-four, non-pregnant, non-lactating women with ID (plasma ferritin $(\mathrm{PF})<15 \mu \mathrm{g} / \mathrm{l}$ ), aged between 18 and 27 years with body weight $<66 \mathrm{~kg}$, were selected from an initial screening of 178 women. Women with known metabolic, chronic and gastro-intestinal diseases, as well as women on long-term medication (except oral contraceptives), were excluded from participating. In addition, smokers, women who did more than $10 \mathrm{~h}$ of intensive sport per week and women who consumed more than fourteen units of alcohol per week were not enrolled. Intake of vitamin and/or mineral supplements was not allowed during and 2 weeks before the study. No women were recruited who had donated blood or experienced substantial blood loss within 6 months of the beginning of the study. The study was conducted according to the guidelines laid down in the Declaration of Helsinki, and all procedures involving human subjects were approved by the cantonal ethics committee in Zurich, Switzerland (approval no. 2014-0279). Written informed consent was obtained from all participants. The study was registered at clinicaltrials.gov (NCT02327299; https://clinicaltrials.gov/ct2/show/NCT02327299).

\section{Absorption study design}

A double-blind, randomised, partial William's cross-over design was used with each woman serving as her own control. Participants received one of four different types of bouillon containing either ${ }^{54} \mathrm{FeSO}_{4},{ }^{54} \mathrm{FeSO}_{4}+\mathrm{NaPP},{ }^{57} \mathrm{FePP}$ or ${ }^{57} \mathrm{FePP}+\mathrm{NaPP}$ on study days 1, 4, 18 and 21, respectively (Fig. 1). The William's cross-over design was partial because the same Fe compounds were labelled with the same isotopes, and could therefore not be administered consecutively on days 1 and 4 or on days 18 and 21. Nevertheless, each of the four bouillon types could have been administered on any study day if some sequences were avoided (e.g. ${ }^{54} \mathrm{FeSO}_{4}$-fortified bouillon was

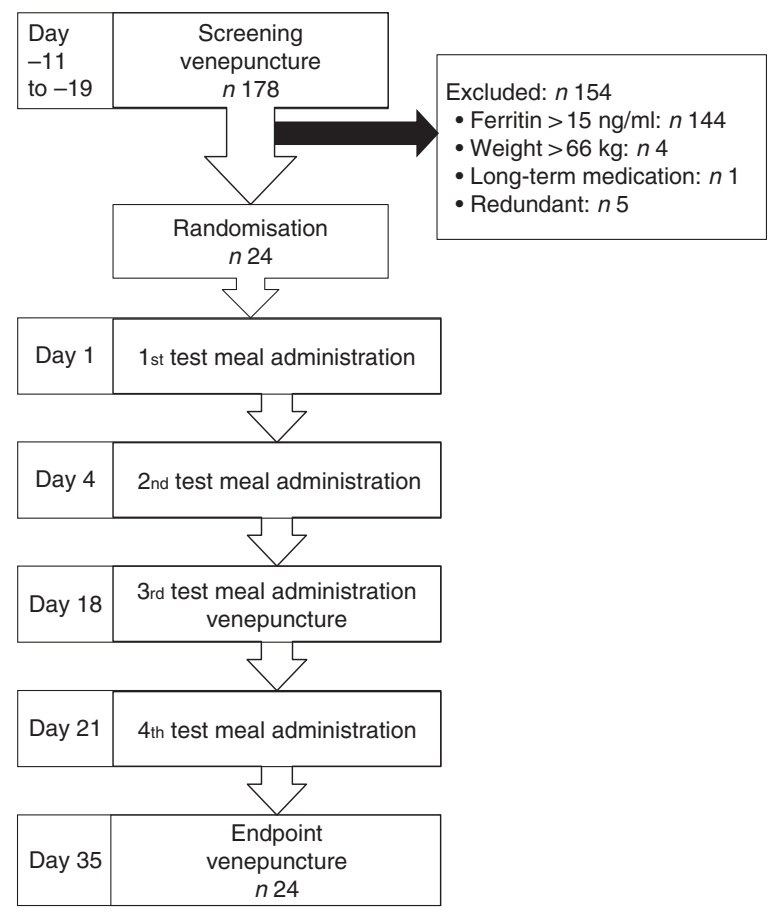

Fig. 1. Schematic diagram of the study design. Four different bouillons containing either ferric pyrophosphate (FePP) only, FePP + tetra sodium pyrophosphate (NaPP), ferrous sulphate $\left(\mathrm{FeSO}_{4}\right)$ only or $\mathrm{FeSO}_{4}+\mathrm{NaPP}$ were randomly administered on days $1,4,18$ or 21, respectively. FePP was labelled with ${ }^{57} \mathrm{Fe}$ isotopes and $\mathrm{FeSO}_{4}$ with ${ }^{54} \mathrm{Fe}$ isotopes; therefore, a partial William's cross-over design was used, meaning that the same isotopes were not administered consecutively on days 1 and 4 or on days 18 and 21 , respectively. In all, twenty-four women from an initial screening of 178 women were selected; there were no dropouts. Redundant participants were participants who were eligible but were not included in the study because the targeted sample size was already reached. The participants were included according to their screening number, meaning that the first twenty-four participants with iron deficiency were included, whereas the additional irondeficient participants were redundant and not included.

administered on days $1,4,18$ or 21 but then ${ }^{54} \mathrm{FeSO}_{4}$-fortified bouillon with NaPP was not given on days $4,1,21$ or 18 , respectively). The labelled Fe-fortified bouillons made from two cubes according to a standard protocol were administered between 06.30 and 09.30 hours after an overnight fast. The participants consumed the complete bouillon $(400 \mathrm{ml})$ and a glass of $160 \mathrm{ml}$ nanopure water in the presence of the investigators and were not allowed to eat for $3 \mathrm{~h}$ after consuming the bouillon. Within $1 \mathrm{~h}$ after meal completion, participants were allowed to drink 330 litres of mineral water (Evian Junior; Evian) provided by the investigators. No other fluids were allowed for $3 \mathrm{~h}$ after completion of the bouillon.

During screening (baseline measurements), 19-11 d before the first bouillon administration, body weight and height of the participants were measured, and a first blood sample was drawn for $\mathrm{Fe}$ status determination $(\mathrm{Hb}, \mathrm{PF}$, soluble transferrin receptor (sTfR), C-reactive protein (CRP), $\alpha$-1-glycoprotein (AGP)). On day 18, a second blood sample was collected for determining Fe status and Fe absorption from the administration of the first and second bouillons. On day 35 (final study day), a third blood sample was drawn for Fe isotopic analysis and determination of Fe status. Fe absorption was determined using 
stable isotope technique, in which the incorporation into erythrocytes of isotopic Fe labels was measured at least $14 \mathrm{~d}$ after the administration of the last bouillon ${ }^{(23)}$. Adverse events and concomitant medication were inquired and documented during the entire study after subject enrolment.

\section{Preparation of bouillon}

Each bouillon cube ( $4 \mathrm{~g}$ ) was intrinsically labelled with $2.5 \mathrm{mg}$ $\mathrm{Fe}$ isotopes as the only source of Fe in the cube. Preparation of bouillon started with boiling nanopur water in a water boiler. Next, $400 \mathrm{~g}$ boiling nanopur water was weighed into a heatresistant glass beaker, and two bouillon cubes (two cube weighing total $8 \mathrm{~g}$, containing $5 \mathrm{mg}$ Fe isotopes) were dissolved in the water. The vial, used for storage and transport of the bouillon cubes, was rinsed with $1 \mathrm{ml}$ boiling nanopur water to dissolve any remaining particles and the rinsing was added to the beaker. Bouillon cubes were dissolved by stirring using a stainless steel spoon until no visible cube particles were left. The bouillon was served to the participants when it had cooled down to a temperature of $58 \pm 2^{\circ} \mathrm{C}$, measured using an infrared thermometer. The empty beaker was rinsed two times with $20 \mathrm{ml}$ boiled nanopur water, and the rinsing liquid was consumed by the participants. To ensure complete intake of bouillon, participants were instructed to clean the stainless steel spoon by licking it and to use a plastic scraper to remove and consume the remaining particles at the bottom of the beaker. After complete consumption of the bouillon, the participants immediately consumed $160 \mathrm{~g}$ nanopur water.

\section{Production of isotopically labelled bouillon cubes}

Isotopically labelled ${ }^{54} \mathrm{FeSO}_{4}$ (monohydrate crystals) and ${ }^{57} \mathrm{FePP}$ with a volume-weighed mean diameter D[4,3] of $18 \cdot 1 \mu \mathrm{m}$ and a surface-weighed mean diameter $\mathrm{D}[3,2]$ of $14.6 \mu \mathrm{m}$ were prepared in powder form by Paul Lohmann $\mathrm{GmbH}$ from isotopically enriched elemental Fe ( ${ }^{54} \mathrm{Fe}$-metal: $99.7 \%$ enriched;

${ }^{57}$ Fe-metal: $96.7 \%$ enriched; all Chemgas).

Bouillon cubes were prepared from the ingredients as in the equivalent commercial product (salt, sugars, starch, vegetable fats, herbs and spices) using a dry-blending protocol at $300 \mathrm{~g}$ scale. Ingredients were added in the order of quantity required, starting with the largest amount by weight (salt), to a small stainless steel bowl blender with K-mixer (Kenwood). The isotopically labelled material $(2.5 \mathrm{mg} \mathrm{Fe} /$ cube $)$ and the NaPP $\left(\mathrm{Na}_{4} \mathrm{P}_{2} \mathrm{O}_{7} ; 12 \mathrm{mg} /\right.$ cube) were added in the final blending step, resulting in approximately 1:1 molar ratio for equivalents (eq.). NaPP:Fe. Blend homogeneity was monitored by visual inspection. From the blend, $4000 \mathrm{mg}$ was accurately weighed $( \pm 10 \mathrm{mg}$ at maximum) and transferred to a stainless steel die for immediate pressing with a fixed end-pressure to obtain bouillon cubes $(14 \times 14 \times 14 \mathrm{~mm})$. Dose and uniformity of dose were checked via the total cube weight variation and by multiple, randomly selected cube Fe analysis.

\section{Measurement of iron in the bouillon cubes}

The Fe concentration and isotopic composition of each type of labelled bouillon cubes was determined in two bouillon cubes, corresponding to the administered dose. Doses of two cubes were mineralised in triplicate by boiling in $50 \mathrm{ml}$ nitric acid $65 \%$ for $12 \mathrm{~h}$, followed by the addition of $3 \mathrm{ml}$ hydrogen peroxide $30 \%$ and further boiling for $2 \mathrm{~h}$. The solutions were then diluted to $300 \mathrm{~g}$ with water. Fe concentration in aliquots of the mineralised samples was determined by inverse isotope dilution mass spectrometry using an Fe standard solution prepared gravimetrically from an Fe isotopic reference material (IRMM-014; EU Institute of Reference Materials). Fe and isotopic label concentrations of two bouillon cubes were expressed as means and standard deviations and used for the calculation of Fe bioavailability.

\section{Blood sample analysis}

Hb was measured in whole blood on the day of collection using a Hemocue during Screening and an automated hematology analyzer (Sysmex Corporation) for follow-up blood samples; anaemia was defined as $\mathrm{Hb}<120 \mathrm{~g} / \mathrm{l}^{(24)}$. PF was measured using an IMMULITE automatic system (Siemens); ID was defined as $\mathrm{PF}<15 \mu \mathrm{g} / \mathrm{l}$ and ID anaemia as $\mathrm{Hb}<120 \mathrm{~g} / \mathrm{l}$ plus $\mathrm{PF}<15 \mu \mathrm{g} / \mathrm{l}^{(24)}$. STfR, AGP and CRP were measured using a combined Sandwich ELISA technique ${ }^{(25)}$; sTfR concentrations $>8.3 \mathrm{mg} / \mathrm{l}$ were considered as second-stage ID, indicating Fe-deficient erythropoiesis. Expected AGP and CRP concentrations for healthy individuals were $<1 \mathrm{~g} / 1$ and $<5 \mathrm{mg} / 1$, respectively ${ }^{(26)}$.

Each isotopically enriched blood sample was analysed in duplicate for its isotopic composition. Whole blood was mineralised by microwave digestion, and Fe was separated by anionexchange chromatography and a subsequent precipitation step with ammonium hydroxide ${ }^{(27)}$. Fe isotope ratios were determined by an MC-ICP-MS instrument (Neptune; Thermo Finnigan).

\section{Calculation of iron bioavailability}

The amounts of ${ }^{54} \mathrm{Fe}$ and ${ }^{57} \mathrm{Fe}$ labels in the blood were calculated on the basis of the shift in Fe isotope ratios in the blood samples collected on days 18 and 35 and the estimated amount of Fe circulating in the body. For the calculation on day 35, the isotopic ratio of day 18 was considered as a new baseline. The changes in circulating isotopic tracer in blood between 14 and at least $35 \mathrm{~d}$ after administration are negligible (unpublished internal data partly based on the study by Petry et $a l .{ }^{(28)}$ ), particularly when taking into account the randomisation of the participants. Therefore, a first dose of isotopes does not affect the bioavailability calculation of a second dose of isotopes, administered at least $14 \mathrm{~d}$ after the first dose. Circulating Fe was calculated on the basis of the blood volume estimated from height and weight and measured $\mathrm{Hb}$ concentration ${ }^{(29)}$. The calculations were based on the principles of isotope dilution, taking into account that Fe isotopic labels were not monoisotopic, using the methods described by Kastenmayer et $a l .{ }^{(30)}$. For calculating Fe bioavailability (fractional $\mathrm{Fe}$ absorption), $80 \%$ incorporation of the absorbed $\mathrm{Fe}$ into erythrocytes was assumed ${ }^{(31)}$.

\section{In vitro studies}

In vitro bioaccessible $\mathrm{Fe}$ was determined using previously described methods ${ }^{(32,33)}$ and are described in detail in the 
online Supplementary Material. In brief, the experiments were carried out in triplicate and were based on simulating gastrointestinal digestion, by exposure of $80 \mathrm{ml}$ bouillons (Fe concentration: $18.75 \mu \mathrm{g} / \mathrm{ml}$ ) to gastric conditions (low $\mathrm{pH}$ and gastric enzymes) followed by intestinal conditions (neutralisation of $\mathrm{pH}$ and incubation with pancreatic enzymes and bile salts). Subsequently, the digested bouillon was dialysed $(<8000 \mathrm{~g} / \mathrm{mol}$ ) and the dialysable $\mathrm{Fe}$ and ionic $\mathrm{Fe}$, using inductively coupled plasma-atomic emission spectrometry and the Ferrozine method ${ }^{(34)}$ with slight alterations to derive a linear response equation, respectively, were determined.

To simulate the cellular absorption of $\mathrm{Fe}$ after gastrointestinal digestion, uptake of Fe by Caco-2 cell monolayers was used. Exposed to ionic Fe, Caco-2 cells synthesise ferritin as response to Fe uptake and the amount is proportional to the Fe content in the culture medium. Cellular ferritin can be a good indicator of the Fe absorbed ${ }^{(35)}$. Ferritin was measured via a commercially available ELISA kit (H-ferritin (human), ELISA kit, Abnova KA0211; Abnova $\mathrm{GmbH}$ ). A control without added Fe and a reference sample $\left(5 \mu \mathrm{m}-\mathrm{FeSO}_{4}\right.$ solution) were included to determine the cell blank and standard responses to confirm validity of the assay.

\section{Statistical analysis}

Analyses were conducted with SAS software version 9.4 and Excel (Windows 7; Microsoft). Results of Fe analysis, age, anthropometric features, $\mathrm{Hb}$, PF, sTfR, AGP and CRP were presented as means and standard deviations if normally distributed. If not normally distributed, the results were presented as geometric mean values with their 95\% CI. The results of $\mathrm{Fe}$ absorption are presented as geometric mean values with their $95 \%$ CI. The study was powered (90\%) to detect an intra-subject difference of $30 \%$ in Fe bioavailability with a two-sided $\alpha$ set at $0 \cdot 05$, and sample size calculation was based on the primary hypothesis for the in vivo study, which was the comparison of FePP-fortified cubes with and without NaPP. Nevertheless, all the differently fortified bouillon cubes were compared using a mixed model ANOVA on the log-transformed Fe bioavailability with subject as a random effect and day of treatment and presence of stabiliser as fixed effects followed by Tukey's adjustment to control the type 1 error to 0.05 over the set of the six potential comparisons; two-sided $P$ values are reported. Fe concentrations in the differently fortified bouillon cubes, dialysable and ionic $\mathrm{Fe}$ and ferritin response for the differently fortified bouillon cubes were compared by one-factor ANOVA followed by Bonferronicorrected multiple comparisons. Differences were considered significant at $P<0.05$. All data were converted to their logarithms for statistical analysis and reconverted for reporting.

\section{Results}

\section{Participant characteristics}

Data of twenty-four women were included in the in vivo study. At baseline, all women had PF concentrations $<15 \mu \mathrm{g} / 1$ and normal CRP concentrations $(<5 \mathrm{mg} / \mathrm{l})$ (Table 1$)$; three of the
Table 1. Age, anthropometric features and $\mathrm{Hb}$, plasma ferritin (PF), soluble transferrin receptor (sTfR), $a-1$-acid glycoprotein (AGP) and C-reactive protein (CRP) concentrations of the participating iron-deficient adult women at baseline

(Mean values and standard deviations; geometric means and $95 \%$ confidence intervals)

\begin{tabular}{lcc}
\hline & \multicolumn{2}{c}{ Summary value $(n$ 24) } \\
\cline { 2 - 3 } Characteristics & Mean & SD \\
\hline Age $($ years $)$ & 21.6 & 2.5 \\
Weight $(\mathrm{kg})$ & 57.2 & 4.5 \\
Height $(\mathrm{cm})$ & 168 & 6 \\
BMl $\left(\mathrm{kg} / \mathrm{m}^{2}\right)$ & 20.4 & 2.0 \\
$\mathrm{Hb}(\mathrm{g} / \mathrm{l})$ & 137 & 12 \\
PF $(\mu \mathrm{g} / \mathrm{l})$ & 9.4 & 3.7 \\
\hline & Geometric mean & $95 \% \mathrm{Cl}$ \\
\hline STfR $(\mathrm{mg} / \mathrm{l})$ & 7.10 & $5.94,8.49$ \\
AGP $(\mathrm{g} / \mathrm{l})$ & 0.48 & $0.40,0.57$ \\
CRP $(\mathrm{mg} / \mathrm{l})$ & 0.61 & $0.39,0.98$ \\
\hline
\end{tabular}

women were anaemic at baseline and six women had Fe-deficient erythropoiesis as indicated by elevated sTfR concentrations. Among all, two women had slightly elevated AGP values at baseline $(1.23$ and $1.01 \mathrm{~g} / \mathrm{l})$, which then decreased $<1.0 \mathrm{~g} / \mathrm{l}$ during the study.

At the second blood sampling, PF concentrations of nine women increased to above $15 \mu \mathrm{g} / \mathrm{l}$. The PF values for these nine women were between 15.1 and $26.8 \mu \mathrm{g} / \mathrm{l}$. At the end point, fourteen women had PF concentrations $<15 \mu \mathrm{g} / \mathrm{l}$ and twenty women $<20 \mu \mathrm{g} / \mathrm{l}$. One woman had slightly elevated CRP concentrations in her second blood sample $(6.2 \mathrm{mg} / \mathrm{l})$, and two women had CRP concentrations $>5 \mathrm{mg} / \mathrm{l}$ at the end point $(5.7$ and $15.3 \mathrm{mg} / \mathrm{l})$.

\section{Iron concentration of bouillon cubes}

The average Fe concentrations in the bouillon cubes fortified with FePP were close to the target of $5 \mathrm{mg} \mathrm{Fe} / 2$ cubes and showed good content uniformity, whereas the average $\mathrm{Fe}$ concentrations in the $\mathrm{FeSO}_{4}$-fortified bouillon cubes were slightly below and above the targeted value. In addition, the variability of $\mathrm{Fe}$ concentration measurements was higher in the bouillon cubes fortified with $\mathrm{FeSO}_{4}$ compared with the FePP-fortified bouillon cubes (Table 2).

\section{In vivo iron bioavailability measurements}

Mean Fe bioavailability from FePP-fortified bouillon cubes plus NaPP was $46 \%$ higher than that from FePP-fortified bouillon cubes without NaPP $(P<0.005)$ (Table 3$)$. In all, twenty-one of the twenty-four women showed higher $\mathrm{Fe}$ absorption from bouillon cubes fortified with FePP + NaPP than from cubes fortified with FePP only. Mean Fe bioavailability from bouillon cubes fortified with $\mathrm{FeSO}_{4}+\mathrm{NaPP}$ did not significantly differ compared with that from $\mathrm{FeSO}_{4}$-fortified bouillon cubes without NaPP $(P=0 \cdot 2)$. The relative bioavailability (RBV) of FePP-fortified bouillon cubes with or without 
Table 2. Total iron and isotopic label concentrations of the four different types of intrinsically labelled bouillon cubes (Mean values and standard deviations)

\begin{tabular}{|c|c|c|c|c|}
\hline \multirow[b]{2}{*}{ Bouillon cube types } & \multicolumn{2}{|c|}{ Total Fe concentration (mg Fe/2 cubes) ${ }^{*}$} & \multicolumn{2}{|c|}{ Isotopic label concentration (mg Fe/2 cubes) ${ }^{\star} \dagger$} \\
\hline & Mean & SD & Mean & SD \\
\hline FePP only & $4 \cdot 8^{\mathrm{a}}$ & 0.2 & $4 \cdot 7^{\mathrm{a}}$ & 0.2 \\
\hline $\mathrm{FePP}+\mathrm{NaPP}$ & $4.9^{\mathrm{a}}$ & 0.5 & $4 \cdot 8^{\mathrm{a}}$ & 0.5 \\
\hline $\mathrm{FeSO}_{4}$ only & $5 \cdot 5^{\mathrm{a}}$ & $2 \cdot 2$ & $5 \cdot 4^{\mathrm{a}}$ & $2 \cdot 2$ \\
\hline $\mathrm{FeSO}_{4}+\mathrm{NaPP}$ & $4 \cdot 4^{\mathrm{a}}$ & $1 \cdot 1$ & $4 \cdot 3^{\mathrm{a}}$ & $1 \cdot 1$ \\
\hline
\end{tabular}

FePP, ferric pyrophosphate; NaPP, sodium pyrophosphate; $\mathrm{FeSO}_{4}$, ferrous sulphate.

${ }^{a}$ Mean values within a column with unlike superscript letter were significantly different $(P<0.05)$

${ }^{*} n 3$ Independent analyses.

† The isotopic label concentration is part of the total $\mathrm{Fe}$ concentration. FePP was labelled with ${ }^{57} \mathrm{Fe}$ isotopes and $\mathrm{FeSO}_{4}$ was labelled with ${ }^{54} \mathrm{Fe}$ isotopes.

Table 3. Iron bioavailability and relative bioavailability per different type of bouillon cubes consumed by iron-deficient women (Geometric mean values and $95 \%$ confidence intervals)

\begin{tabular}{|c|c|c|c|}
\hline \multirow[b]{2}{*}{ Bouillon cube types } & \multicolumn{2}{|c|}{$\begin{array}{c}\text { Fe absorption }(n 24) \\
(\% \text { of dose })\end{array}$} & \multirow[b]{2}{*}{ Relative bioavailability (\%) } \\
\hline & Geometric mean & $95 \% \mathrm{Cl}$ & \\
\hline FePP only & $4 \cdot 4^{\mathrm{a}}$ & $3.9,4.9$ & 13 \\
\hline $\mathrm{FePP}+\mathrm{NaPP}$ & $6 \cdot 4^{b}$ & $5 \cdot 7,7 \cdot 2$ & 19 \\
\hline $\mathrm{FeSO}_{4}$ only & $33 \cdot 8^{c}$ & $27 \cdot 7,41 \cdot 3$ & 100 \\
\hline $\mathrm{FeSO}_{4}+\mathrm{NaPP}$ & $27 \cdot 8^{\mathrm{c}}$ & $22 \cdot 8,33 \cdot 9$ & 82 \\
\hline
\end{tabular}

FePP, ferric pyrophosphate; NaPP, sodium pyrophosphate; $\mathrm{FeSO}_{4}$, ferrous sulphate.

a,b,c Mean values within a column with unlike superscript letters were significantly different $(P<0.0001)$.

* Relative to the bioavailability from $\mathrm{FeSO}_{4}$ only $(100 \%)$.

NaPP was $<20 \%$, and the mean Fe bioavailability was between 4.3 and 7.7 times lower than that from bouillon cubes fortified with $\mathrm{FeSO}_{4}$ with or without NaPP, respectively (all $P<0 \cdot 0001$ ).

\section{In vitro iron measurements}

The in vitro Fe accessibility by the digestion protocol showed a clear effect of the addition of the stabiliser for FePP, but not for $\mathrm{FeSO}_{4}$ (Fig. 2). The dialysable $\mathrm{Fe}(P=0.008)$ and ionic $\mathrm{Fe}$ $(P=0.012)$ were significantly higher for cubes fortified with FePP + NaPP (1.36 (sD 0.23) mg/l and 34.7 (sD 3.2)\%, respectively) than for FePP only $(0.85$ (SD 0.08$) \mathrm{mg} / \mathrm{l}$ and 18.7 (sD 5.3)\%, respectively). The dialysable $\mathrm{Fe}$ for $\mathrm{FeSO}_{4}$ only $\left(2.33\right.$ (sD 0.25) mg/l) and $\mathrm{FeSO}_{4}+\mathrm{NaPP}(3.13$ (sD 0.11) mg/l) was significantly higher than that from $\mathrm{FePP}+\mathrm{NaPP}$ and from FePP $(P<0.005)$. This was different for the ionic Fe where FePP+NaPP was not different from $\mathrm{FeSO}_{4}$ only (39.4 (SD 5.8)\%) and $\mathrm{FeSO}_{4}+\mathrm{NaPP}(50 \cdot 6$ (SD 4.4)\%).

The cellular ferritin responses generally showed higher variability (Fig. 2), and bouillons with FePP only (7.8 (sD 2.2) ng ferritin/mg protein) did not differ from FePP $+\mathrm{NaPP}$ (12.0 (sD 3.7) $\mathrm{ng} / \mathrm{mg}$ ). The only significant difference was found for $\mathrm{FeSO}_{4}+\mathrm{NaPP} \quad(40.8$ (SD 14.8$) \mathrm{ng} / \mathrm{mg}$ ) compared with FePP only $(P=0.008)$ and FePP $+\mathrm{NaPP} \quad(P=0.046)$. There was a tendency for an increased ferritin response for $\mathrm{FeSO}_{4}+\mathrm{NaPP}$ compared with $\mathrm{FeSO}_{4}$ only (14.4 (SD 7.0) ng/mg; $P=0 \cdot 076)$.

\section{Discussion}

The major finding of the current study is the enhancing effect of NaPP on Fe absorption from bouillon cubes fortified with FePP. To our knowledge, this is the first time that the effect of NaPP on Fe bioavailability has been investigated and NaPP has never been reported as an enhancer of Fe absorption. Previous studies have shown that Fe bioavailability from FePP-fortified infant cereals can be enhanced by the addition of ascorbic acid, but to a lesser extent than from $\mathrm{FeSO}_{4}{ }^{(19,36)}$. Whereas the enhancing effect of ascorbic acid on human non-haem Fe absorption is related to the reducing and chelating properties of ascorbic acid during digestion of the food ${ }^{(20)}$, our in vitro experiments suggest that NaPP may enhance bioavailability by forming soluble complexes of $\mathrm{Fe}$ and pyrophosphate anions, such as $\mathrm{P}_{2} \mathrm{O}_{7}{ }^{4-}$ and $\mathrm{HP}_{2} \mathrm{O}_{7}{ }^{3-}$, hence increasing the amount of soluble ionic $\mathrm{Fe}$, which is essential for intestinal Fe uptake. A previous study suggests that these complexes still exist at the neutral $\mathrm{pH}$ of the gastro-intestinal milieu. This is in contrast to most of the other ionic $\mathrm{Fe}$ compounds that form insoluble complexes at neutral $\mathrm{pH}^{(22)}$.

The enhancing effect of NaPP on Fe absorption from FePP suggests that the addition of this salt could be used as an enhancer in other foods preferentially fortified with FePP, such as extruded rice, or infant cereals. In these foods, NaPP could enhance the low Fe bioavailability from FePP significantly. However, we tested the enhancing effect of NaPP on FePP using a comparably simple test (bouillon cubes dissolved in water) containing no or negligible amounts of Fe absorption 
(A)

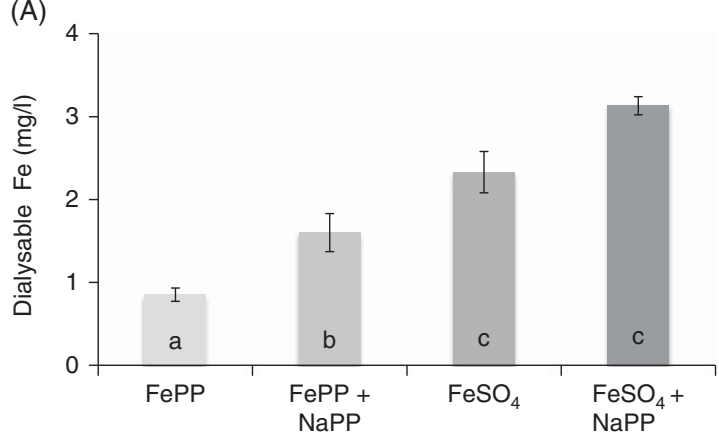

(B)

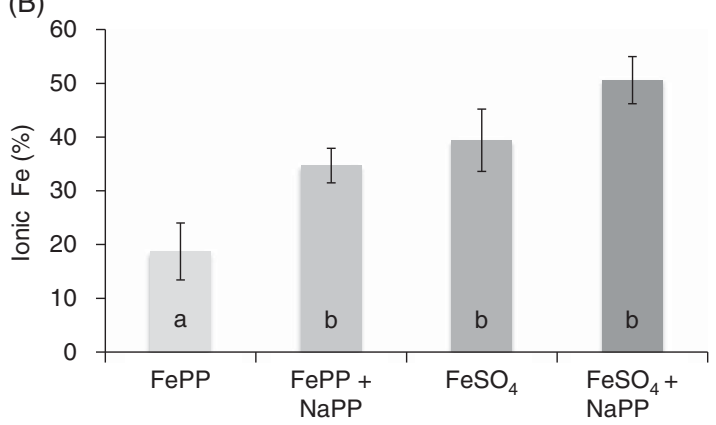

(C)

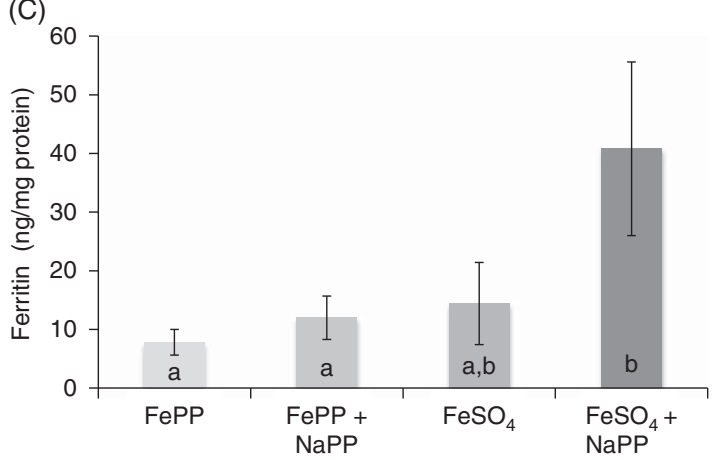

Fig. 2. Results of the in vitro experiments for the four different bouillons containing either ferric pyrophosphate (FePP) only, FePP + tetra sodium pyrophosphate $(\mathrm{NaPP})$, ferrous sulphate $\left(\mathrm{FeSO}_{4}\right)$ only or $\mathrm{FeSO}_{4}+\mathrm{NaPP}$. Bars represent dialysable $(\mathrm{A})$ and ionic $\mathrm{Fe}(\mathrm{B})$ from simulated gastric and small intestinal digestion and ferritin response (C) from Caco-2-cell assay. Error bars with whiskers indicate standard deviations $(n 3) .{ }^{\mathrm{a}, \mathrm{b}, \mathrm{c}}$ Mean values with unlike letters were significantly different in an one-way ANOVA followed by Bonferroni correction for multiple comparison $(P<0.05)$.

inhibitors and only at one fixed molar ratio (approximately 1:1 for eq. NaPP:Fe). In vitro data investigating the dissolution behaviour of FePP in the presence of NaPP suggest that a higher ratio of NaPP:FePP (>1 eq.) could further improve the Fe bioavailability, because multiple pyrophosphate ligands per $\mathrm{Fe}$ cation would be available to form soluble complexes ${ }^{(22)}$. Food matrix is known to affect bioavailability of $\mathrm{FePP}^{(36)}$, and in complete meals, containing phytic acid, polyphenols and other common food ingredients known to inhibit Fe absorption ${ }^{(37-39)}$, the enhancing effect of NaPP may be modulated by the food matrix. Therefore, further investigation is needed to understand $\mathrm{NaPP}$ effects. In the present study, NaPP at the tested ratio did not increase the Fe bioavailability of $\mathrm{FeSO}_{4}$; nevertheless, it would be of interest to investigate whether NaPP has an enhancing effect of Fe absorption from other Fe compounds, particularly the water-insoluble compounds.

The current study using FePP with a regular mean particle size, comparable with the commercially available FePP, confirms the rather low bioavailability of FePP found in previous human studies, where Fe bioavailability from FePP with regular particle size was significantly lower than that from other Fe compounds used to fortify infant cereals ${ }^{(40)}$ or full-cream milk powder ${ }^{(41)}$. On the basis of a human study using FePP with a markedly reduced average particle size $(\mathrm{D}[3,2]=0.30 \mu \mathrm{m})$, where Fe bioavailability from FePP-fortified infant cereals and yogurt drinks was not different compared with that from $\mathrm{FeSO}_{4}{ }^{(42)}$, reducing the particle size of FePP has been suggested to potentially increase its bioavailability. However, in another study, micronised dispersible FePP with $\mathrm{D}[3,2]$ of $0.77 \mu \mathrm{m}$ had a lower Fe bioavailability from infant cereals and rice than $\mathrm{FeSO}_{4}$ despite the small particle size ${ }^{(36)}$. Owing to the difficulties in manufacturing labelled compounds with small particle size that closely mimic the commercially available compounds, it remains unclear whether the reduction of the particle size would further increase the bioavailability from FePP. The distinctly reduced RBV of FePP to $\mathrm{FeSO}_{4}$ in the present study is mainly due to the insolubility of FePP, but at some extent can also be explained by the low Fe status of the participating women as the RBV of FePP decreases with decreasing $\mathrm{Fe}$ status ${ }^{(36)}$ as a result of the up-regulated bioavailability of $\mathrm{FeSO}_{4}$ in subjects with low or absent $\mathrm{Fe}$ stores ${ }^{(43)}$. Whether the RBV of FePP from fortified bouillon cubes would be different in more complex meals due to the presence of enhancers and inhibitors, which would differently affect the bioavailability of FePP and $\mathrm{FeSO}_{4}$, needs further investigation.

In sub-Saharan Africa, bouillon cubes are reported to be consumed frequently, and the estimated median intakes in women in Burkina Faso, Cameroon, Niger and Senegal ranged between 2.1 and 4.3 and between 0.7 and $3.6 \mathrm{~g} / \mathrm{d}$ in urban and non-urban areas, respectively ${ }^{(9)}$. Our study suggests that in populations where the daily consumption of bouillon cubes is approximately $4 \mathrm{~g} / \mathrm{d}$ per capita, cubes fortified with $2.5 \mathrm{mg}$ Fe could provide between 0.7 and $0.9 \mathrm{mg}$ Fe when fortified with $\mathrm{FeSO}_{4}$ and between 0.1 and $0.2 \mathrm{mg}$ when fortified with FePP, which is between 48 and $58 \%$ and between 7 and $11 \%$ of the median daily $\mathrm{Fe}$ requirements for menstruating women older than 18 years ${ }^{(44)}$, respectively. These estimations indicate that higher fortification levels of FePP or higher intakes of FePPfortified cubes than the current estimated median intake of bouillon cubes may be required to cover $20-30 \%$ of the Fe requirements in women older than 18 years. In addition, it has to be stressed that extrapolation of our data is limited, as in subSaharan Africa bouillon cubes are used in complex meals that likely contain considerable amounts of Fe absorption inhibitors, such as phytic acid and polyphenols ${ }^{(45)}$, and therefore $\mathrm{Fe}$ bioavailability is likely to be lower than what has been measured in the present study. Therefore, our data suggest that $\mathrm{FeSO}_{4}$ would provide the highest amount of $\mathrm{Fe}$ and may be the preferred fortificant for bouillon cubes. However, product stability and sensorial characteristics are insufficient when using $\mathrm{FeSO}_{4}$, and therefore FePP likely remains the Fe compound of 
choice for bouillon cubes. With regard to Na intake, which because of the risk of hypertension is a point of concern in savoury consumer products, the addition of NaPP as absorption enhancer in the present study only minutely increased the $\mathrm{Na}$ intake by $12 \mathrm{mg} /$ cube. Compared with the common $\mathrm{Na}$ concentration in bouillon cubes (approximately $0.8 \mathrm{~g} /$ cube) and the WHO recommendation for daily Na intake $(<2 \mathrm{~g} / \mathrm{d})^{(46)}$, this would be a negligible increase.

Our combined approach of in vitro and in vivo studies confirms that dialysability and simulated gastrointestinal digestion in Caco-2 cell models can be a useful screening tool to understand factors that may affect $\mathrm{Fe}$ absorption ${ }^{(47)}$. Whereas the results of the dialysable Fe were in complete agreement with the in vivo results, measurement of in vitro ionic Fe only showed the enhancing effect of NaPP on Fe bioavailability from FePP. These results and the high variability in Caco- 2 cell ferritin responses confirm the need to ultimately investigate $\mathrm{Fe}$ absorption in humans ${ }^{(48)}$. Discrepancies in the quantitative assessment between in vitro and in vivo methods assessing Fe bioavailability are well documented and are likely due to factors such as Fe status or dose of administered $\mathrm{Fe}$, which can only be taken into account in in vivo studies ${ }^{(49)}$. A limitation of the present study was the relatively high variability of $\mathrm{Fe}$ concentration in the intrinsically labelled bouillon cubes fortified with $\mathrm{FeSO}_{4}$, and this may have increased measurement error in the bioavailability assessment of the $\mathrm{FeSO}_{4}$-fortified bouillon cubes.

Using intrinsically labelled bouillon cubes, our study shows for the first time that NaPP increases bioavailability of FePP. Although this enhancement does not match the high bioavailability obtained with $\mathrm{FeSO}_{4}$, the use of $\mathrm{NaPP}$ as an $\mathrm{Fe}$ absorption enhancer for FePP is a promising approach for bouillon cubes. Further research is now needed to investigate the effects of NaPP in composite meals prepared with Fe-fortified bouillon cubes and containing $\mathrm{Fe}$ absorption inhibitors and enhancers, in other fortified foods and in the long-term perspective.

\section{Acknowledgements}

The authors thank Carole Verhoeven, Unilever R\&D, Vlaardingen, The Netherlands, for her contribution to the study, and Jeoffrey Jansen and Monique van der Burg-Koorevaar, both Unilever R\&D, Vlaardingen, The Netherlands, for the instrumental help in the production and testing of the bouillon cubes. The authors also thank Laura Hackl, Tanja Barth-Jaeggi and Laura Cascales, all Human Nutrition Laboratory, ETH Zurich, Switzerland, for their assistance during screening.

The present study was financially supported by Unilever R\&D, Vlaardingen, the Netherlands. G. S. M. J. E. D., W. P. K., R. v. d. B., R. K. H. and P. M. all employees of Unilever R\&D, contributed to the study design, conduct of the study, analysis of data and the preparation of the manuscript. The intrinsically labelled bouillon cubes were prepared by Unilever R\&D.

C. I. C., W. P. K., R. K. H., R. v. d. B., G. S. M. J. E. D., M. B. Z. and D. M. designed the study; C. I. C., D. M., C. Z. and G. S. M. J. E. D. conducted the study; C. I. C., C. Z., P. M., G. S. M. J. E. D. analysed the data; C. I. C., G. S. M. J. E. D.,
M. B. Z. and D. M. wrote the paper; C. I. C., M. B. Z. and D. M. had primary responsibility for final content. All the authors read and approved the final version of the manuscript.

C. I. C., D. M., C. Z. and M. B. Z. have no conflicts of interest. G. S. M. J. E. D., W. P. K., R. v. d. B., R. K. H. and P. M. are all employees of Unilever R\&D, which markets bouillon cubes.

\section{Supplementary material}

For supplementary material/s referred to in this article, please visit http://dx.doi.org/10.1017/S0007114516002191

\section{References}

1. Kassebaum NJ, Jasrasaria R, Naghavi M, et al. (2014) A systematic analysis of global anemia burden from 1990 to 2010. Blood 123, 615-624.

2. Hurrell R, Ranum P, de Pee S, et al. (2010) Revised recommendations for iron fortification of wheat flour and an evaluation of the expected impact of current national wheat flour fortification programs. Food Nutr Bull 31, S7-S21.

3. Zimmermann MB, Wegmueller R, Zeder C, et al. (2004) Triple fortification of salt with microcapsules of iodine, iron, and vitamin A. Am J Clin Nutr 80, 1283-1290.

4. Ballot DE, Macphail AP, Bothwell TH, et al. (1989) Fortification of curry powder with NaFe(III)EDTA in an iron-deficient population - report of a controlled iron-fortification trial. Am J Clin Nutr 49, 162-169.

5. Chen J, Zhao X, Zhang X, et al. (2005) Studies on the effectiveness of NaFeEDTA-fortified soy sauce in controlling iron deficiency: a population-based intervention trial. Food Nutr Bull 26, 177-186.

6. Zimmermann MB, Wegmueller R, Zeder C, et al. (2004) Dual fortification of salt with iodine and micronized ferric pyrophosphate: a randomized, double-blind, controlled trial. Am J Clin Nutr 80, 952-959.

7. Andersson M, Thankachan P, Muthayya S, et al. (2008) Dual fortification of salt with iodine and iron: a randomized, double-blind, controlled trial of micronized ferric pyrophosphate and encapsulated ferrous fumarate in southern India. Am J Clin Nutr 88, 1378-1387.

8. Engle-Stone R, Ndjebayi AO, Nankap M, et al. (2012) Consumption of potentially fortifiable foods by women and young children varies by ecological zone and socio-economic status in Cameroon. J Nutr 142, 555-565.

9. Hess SY, Brown KH, Sablah M, et al. (2013) Results of Fortification Rapid Assessment Tool (FRAT) surveys in sub-Saharan Africa and suggestions for future modifications of the survey instrument. Food Nutr Bull 34, 21-38.

10. Staubli-Asobayire F (2000) Development of a food fortification strategy to combat iron deficiency in the Ivory Coast. PhD Thesis, ETH Zurich.

11. Bovell-Benjamin AC, Viteri FE \& Allen LH (1999) Sensory quality and lipid oxidaton of maize porridge as affected by iron amino acid chelate and EDTA. J Food Sci 64, 371.

12. Hurrell R (2007) Linking the bioavailability of iron compounds to the efficacy of iron-fortified foods. Int J Vitam Nutr Res $\mathbf{7 7}$, 166-173.

13. Moretti D, Lee TC, Zimmermann MB, et al. (2005) Development and evaluation of iron-fortified extruded rice grains. J Food Sci 70, S330-S336.

14. Hurrell RF, Furniss DE, Burri J, et al. (1989) Iron fortification of infant cereals: a proposal for the use of ferrous fumarate or ferrous succinate. Am J Clin Nutr 49, 1274-1282. 
15. Hurrell RF, Reddy MB, Dassenko SA, et al. (1991) Ferrous fumarate fortification of a chocolate drink powder. Br J Nutr 65, 271-283.

16. Moretti D, Zimmermann MB, Muthayya S, et al. (2006) Extruded rice fortified with micronized ground ferric pyrophosphate reduces iron deficiency in Indian schoolchildren: a double-blind randomized controlled trial. Am J Clin Nutr $\mathbf{8 4}$, 822-829.

17. Blanco-Rojo R, Perez-Granados AM, Toxqui L, et al. (2011) Efficacy of a microencapsulated iron pyrophosphate-fortified fruit juice: a randomised, double-blind, placebo-controlled study in Spanish iron-deficient women. Br J Nutr 105, 1652-1659.

18. Wegmuller R, Camara F, Zimmermann MB, et al. (2006) Salt dual-fortified with iodine and micronized ground ferric pyrophosphate affects iron status but not hemoglobin in children in Cote d'Ivoire. J Nutr 136, 1814-1820.

19. Fidler MC, Davidsson L, Zeder C, et al. (2004) Effect of ascorbic acid and particle size on iron absorption from ferric pyrophosphate in adult women. Int J Vitam Nutr Res 74, 294-300.

20. Hurrell RF, Lynch S, Bothwell T, et al. (2004) Enhancing the absorption of fortification iron. A SUSTAIN Task Force report. Int J Vitam Nutr Res 74, 387-401.

21. Belitz HD, Grosch W, Schieberle P, et al. (2009) Food Chemistry, 4th ed. Berlin: Springer.

22. Tian T, Blanco E, Smoukov SK, et al. (2016) Dissolution behaviour of ferric pyrophosphate and its mixtures with soluble pyrophosphates: potential strategy for increasing iron bioavailability. Food Chem 208, 97-102.

23. Walczyk T, Davidsson L, Zavaleta N, et al. (1997) Stable isotope labels as a tool to determine the iron absorption by Peruvian school children from a breakfast meal. Fresen J Anal Chem 359, 445-449.

24. World Health Organization, United Nations International Children Emergency Fund \& United Nations University (2001) Iron Deficiency Anemia: Assessment, Prevention and Control. Geneva: WHO

25. Erhardt JG, Estes JE, Pfeiffer CM, et al. (2004) Combined measurement of ferritin, soluble transferrin receptor, retinol binding protein, and C-reactive protein by an inexpensive, sensitive, and simple sandwich enzyme-linked immunosorbent assay technique. J Nutr 134, 3127-3132.

26. Dati F, Schumann G, Thomas L, et al. (1996) Consensus of a group of professional societies and diagnostic companies on guidelines for interim reference ranges for 14 proteins in serum based on the standardization against the IFCC/BCR/ CAP reference material (CRM 470). Eur J Clin Chem Clin Biochem 34, 517-520.

27. Hotz K, Krayenbuehl PA \& Walczyk T (2012) Mobilization of storage iron is reflected in the iron isotopic composition of blood in humans. J Biol Inorg Chem 17, 301-309.

28. Petry N, Rohner F, Gahutu JB, et al. (2016) In Rwandese women with low iron status, iron absorption from low-phytic acid beans and biofortified beans is comparable, but lowphytic acid beans cause adverse gastrointestinal symptoms. J Nutr 146, 970-975.

29. Brown E, Hopper J Jr, Hodges JL Jr, et al. (1962) Red cell, plasma, and blood volume in the healthy women measured by radiochromium cell-labeling and hematocrit. J Clin Invest 41, 2182-2190.

30. Kastenmayer P, Davidsson L, Galan P, et al. (1994) A double stable isotope technique for measuring iron absorption in infants. Br J Nutr 71, 411-424.

31. Hosain F, Marsaglia G, Noyes W, et al. (1962) The nature of internal iron exchange in man. Trans Assoc Am Physicians 75, 59-63.
32. Miller DD, Schricker BR, Rasmussen RR, et al. (1981) An in vitro method for estimation of iron availability from meals. Am J Clin Nutr 34, 2248-2256.

33. Luten J, Crews H, Flynn A, et al. (1996) Interlaboratory trial on the determination of the in vitro iron dialysability from food. J Sci Food Agric 72, 415-424.

34. Viollier E, Inglett PW, Hunter K, et al. (2000) The ferrozine method revisited: $\mathrm{Fe}(\mathrm{II}) / \mathrm{Fe}(\mathrm{III})$ determination in natural waters. Appl Geochem 15, 785-790.

35. Glahn RP, Lee OA, Yeung A, et al. (1998) Caco-2 cell ferritin formation predicts nonradiolabeled food iron availability in an in vitro digestion/Caco-2 cell culture model. J Nutr 128, $1555-1561$

36. Moretti D, Zimmermann MB, Wegmuller R, et al. (2006) Iron status and food matrix strongly affect the relative bioavailability of ferric pyrophosphate in humans. Am J Clin Nutr $\mathbf{8 3}$, 632-638.

37. Hurrell RF (2004) Phytic acid degradation as a means of improving iron absorption. Int J Vitam Nutr Res 74, 445-452.

38. Cercamondi CI, Egli IM, Zeder C, et al. (2013) Sodium iron EDTA and ascorbic acid, but not polyphenol oxidase treatment, counteract the strong inhibitory effect of polyphenols from brown sorghum on the absorption of fortification iron in young women. Br J Nutr 111, 1-9.

39. Armah SM, Carriquiry A, Sullivan D, et al. (2013) A complete diet-based algorithm for predicting nonheme iron absorption in adults. $J$ Nutr 143, 1136-1140.

40. Davidsson L, Kastenmayer P, Szajewska H, et al. (2000) Iron bioavailability in infants from an infant cereal fortified with ferric pyrophosphate or ferrous fumarate. Am J Clin Nutr $\mathbf{7 1}$, 1597-1602.

41. Walczyk T, Kastenmayer P, Storcksdieck Genannt Bonsmann S, et al. (2013) Ferrous ammonium phosphate (FeNH(4)PO(4)) as a new food fortificant: iron bioavailability compared to ferrous sulfate and ferric pyrophosphate from an instant milk drink. Eur J Nutr 52, 1361-1368

42. Fidler MC, Walczyk T, Davidsson L, et al. (2004) A micronised, dispersible ferric pyrophosphate with high relative bioavailability in man. BrJ Nutr 91, 107-112.

43. Zimmermann MB, Biebinger R, Egli I, et al. (2011) Iron deficiency up-regulates iron absorption from ferrous sulphate but not ferric pyrophosphate and consequently food fortification with ferrous sulphate has relatively greater efficacy in iron-deficient individuals. Br J Nutr 105, 1245-1250.

44. Food and Agriculture Organization, World Health Organization \& UNU (2004) Vitamin and Mineral Requirements in Human Nutrition. Report of A Joint FAO/WHO Expert Consultation, 2nd ed. Bangkok: FAO/WHO.

45. Cercamondi CI, Icard-Verniere C, Egli IM, et al. (2014) A higher proportion of iron-rich leafy vegetables in a typical Burkinabe maize meal does not increase the amount of iron absorbed in young women. J Nutr 144, 1394-1400.

46. World Health Organization (2012) Guideline: Sodium Intake for Adults and Children. Geneva: WHO.

47. Sandberg AS (2005) Methods and options for in vitro dialyzability: benefits and limitations. Int J Vitam Nutr Res $\mathbf{7 5}$, 395-404.

48. Fairweather-Tait S, Phillips I, Wortley G, et al. (2007) The use of solubility, dialyzability, and Caco-2 cell methods to predict iron bioavailability. Int J Vitam Nutr Res 77, 158-165.

49. Fairweather-Tait S, Lynch S, Hotz C, et al. (2005) The usefulness of in vitro models to predict the bioavailability of iron and zinc: a consensus statement from the HarvestPlus expert consultation. Int J Vitam Nutr Res $\mathbf{7 5}$, 371-374. 